\title{
Circulating Progesterone Concentrations in Cows during Early Pregnancy and Embryonic Mortality Condition
}

\author{
Pinki Rani ${ }^{1 *}$, R.K. Chandolia ${ }^{1}$, Ravi Dutt ${ }^{1}$, Nitin Soni ${ }^{1}$, Anand Kumar Pandey ${ }^{2}$, \\ Gyan Singh $^{2}$, Sandeep Kumar ${ }^{1}$ and S.S. Dhaka ${ }^{3}$
}

${ }^{1}$ Department of Veterinary Gynaecology and Obstetrics, ${ }^{2}$ Department of Veterinary Clinical Complex, ${ }^{3}$ Department of Animal Genetics and Breeding, Lala Lajpat Rai University of Veterinary and animal Sciences, Hisar (Haryana) India 125004 India

*Corresponding author

\author{
A B S T R A C T
}

Keywords

Cows, Embryonic mortality,

Hardhenu,

Progesterone,

Sahiwal

\section{Article Info}

Accepted:

10 June 2018

Available Online:

10 July 2018
The present study was conducted with the objectives to assess the circulating plasma progesterone concentrations in early pregnant cows and in those who suffered embryonic mortality. From the entire herd, a total of 142 (Sahiwal 29 and Hardhenu 113) cows were selected for the study. Out of 142 animals, only 53 animals exhibited non-return to estrus and rest showed estrus signs and behaviour before day 28 post-insemination. Blood sampling from all the 142 animals was carried out on day 15 post-insemination and later from the animals which were confirmed pregnant on day 28 (53 animals) and 45 (51 animals). Animals which were diagnosed with embryonic mortality on day 45 were also subjected to blood sampling. The plasma progesterone concentrations were significantly higher in pregnant cows on all days (Day 15, 28 and 45) as compared to cows with embryonic mortality. The plasma progesterone concentrations in pregnant cows increased significantly $(\mathrm{p}<0.05)$ from $1.78 \pm 0.05$ (Day 15) to $3.23 \pm 0.04$ (Day 45). The plasma progesterone concentrations in cows with embryonic mortality increased remarkably from $0.75 \pm 0.05$ (Day 15) to $1.35 \pm 0.15$ (Day 28). Therefore, the animals suffered with embryonic mortality had lower progesterone concentrations on day 15, 28 and 45 postinsemination than the animals with normal pregnancy. Therefore, luteal insufficiency or other external factors could have been the cause of embryonic mortality.

\section{Introduction}

Embryonic mortality (EM) refers to loss of the conceptus during the first 45 days of pregnancy, which is the period from conception to completion of differentiation (Committee on Reproductive Nomenclature,
1972). Approximately $30 \%$ of pregnancies are lost in the form of embryonic demise and this increases the successive calving interval thereby ultimately affecting the success of reproductive programs in dairy cows (Chaudhary and Purohit, 2012). Early embryonic mortality is a major source of 
economic loss with mortality rate upto $40 \%$ in animal production through repeat breeding and increased cost of artificial insemination (Sreenan and Diskin, 1986; Zavy, 1994; Bajaj, 2001) cost of treatment, extended calving intervals and prolonged dry period resulting in reduced milk production (Roche et al., 1981) and reduced net calf crop (Maurer and Chenault, 1983). Earlier, it was believed that the bovine conceptus gets reabsorbed, but trans-rectal ultrasound examination had demonstrated that the conceptus and its breakdown products apparently are eliminated by expulsion through the cervix, which either goes unnoticed or appear as a vulvar discharge of clear mucus (Kastelic et al., 1991). Also some infectious and hormonal factors may participate in embryonic mortalities (Companile et al., 2007; Bajaj and Sharma, 2011). Some viral, bacterial, protozoal and possibly mycoplasmal infections can result in embryonic death, indirectly by systemic effects via septicemia, viremia or toxemia in the dam or directly by affecting the embryo or contaminating uterine environment. EM caused by systemic pathogens is usually related to fever during the infection. High fever present in the first stage of pregnancy can lead to early embryonic death as a result of denaturation of embryonic proteins.

Prostaglandins, which may be elevated in febrile states, can cause luteolysis and subsequent loss of pregnancy (Vanroose et al., 2000). Among hormonal factors, progesterone $\left(\mathrm{P}_{4}\right)$ is required not only to maintain a suitable uterine environment but also to facilitate the elongation of conceptus and consequent secretion of interferon-tau $(\tau)$. Systemic concentrations of progesterone during the cycles both preceding and following insemination affect embryonic survival; too high or too low a concentration has been shown to be negatively associated with embryonic survival rate. Therefore, optimum secretion of $\mathrm{P}_{4}$ during early luteal phase is essential for successful establishment of pregnancy. Luteal insufficiency during postinsemination period is considered as one of the predisposing factor leading to embryonic mortality (Diskin and Moris, 2008). Therefore, the present study was conducted with the objectives to assess the circulating blood progesterone concentrations in early pregnant cows and in those who suffered embryonic mortality.

\section{Materials and Methods}

\section{Location of the study}

The present study was carried out in the herd of Sahiwal and Hardhenu cows at the Cattle farm situated at North Latitude (NL) $29^{\circ} 8^{\prime}$ 39"; East Longitude (EL) $75^{\circ}$ 41' 44", Department of Animal Genetics and Breeding, Lala Lajpat Rai University of Veterinary and Animal Sciences, Hisar (Haryana) between July to December, 2017. The temperature and relative humidity during the study period ranged between 17.8 to $31.2^{\circ} \mathrm{C}$ and 49.48 to $88.45 \%$ respectively.

\section{Experimental animals and management}

From the entire herd, a total of 142 (Sahiwal 29 and Hardhenu 113) cows were selected for the study. Animals selected for experiments were in average to good body condition, the body condition score (BCS) ranged over 2.5 on a scale from 1 to 5 . BCS was recorded through the period of experiment at weekly intervals. All animals were free from any kind of anatomical and reproductive disorders and clinically healthy. Estrus detection was done by parading a teaser bull daily during morning and evening. The age group and body weight of the animals ranged between 2.5 to 11 years and 300 to $500 \mathrm{~kg}$, respectively. Cows selected for the experiment were housed in half walled pucca sheds with asbestos sheet roof. Cows were stall-fed with adequate quantity of green fodder and wheat-bhoosa. 
Concentrate feed, supplemented with mineral mixture and common salt, was also provided. The feed requirement was adjusted keeping in view milk yield of individual cows. Drinking water was provided $a d$. lib. Animals were well protected from inclement weather.

\section{Artificial insemination (AI)}

All the 142 animals detected at spontaneous estrus were subjected to artificial insemination at the end of standing heat according to $\mathrm{AM} / \mathrm{PM}$ rule i.e. if animal was detected at estrus in the morning, the AI was performed in the evening on the same day and if the animal was detected in the estrus in the evening, AI was performed in the next morning. All the animals were inseminated with elite quality frozen semen after proper thawing. The technique adopted was recto-vaginal and site of semen deposition was body of the uterus. Out of 142 animals, only 53 animals exhibited non-return to estrus and rest showed estrus signs and behaviour before day 28 postinsemination.

\section{Collection and processing of blood samples}

First of all, documentation of the signalment of the animal was done on the data collection sheet. The animals were effectively and humanely restrained to avoid injury to the animal and/or study personnel. Using the halter, animal's head was positioned so that it is slightly elevated and drawn to the side opposite the jugular vein to be sampled. After this, disinfection of venipuncture area was done with spirit swab. Jugular groove was located in the lower neck by occluding the vein with applying digital pressure. Then, a 20 gauge 1 inch vacutainer needle attached to a vacutainer holder was inserted into the distended jugular vein at a $45^{\circ}$ angle cranial to the jugular groove. Once needle is positioned in the vein, $9 \mathrm{ml}$ vacutainer containing EDTA was inserted into the needle to collect the blood. After collection of desired volume (5 $\mathrm{ml}$ ) of blood, occluding pressure from the vein was removed. And vacutainer tube was detached from the needle and the needle withdrawn from the jugular vein. Blood sampling from all the 142 animals was carried out on day 15 post-insemination and later from the animals which were confirmed pregnant ultrasonographically on day 28 (53 animals) and 45 (51 animals). Animals which were diagnosed with embryonic mortality ultrasonographically on day 45 were also subjected to blood sampling. Finally labeling was done on the vacutainer tubes with the sample ID. These collected blood samples were centrifuged at $3000 \mathrm{rpm}$ for 10 minutes using Sigma centrifuge machine for separation of plasma. The plasma was stored in $2 \mathrm{ml}$ aliquots (duplicates) in at $-20^{\circ} \mathrm{C}$ till the estimation of progesterone levels and later the plasma concentrations were estimated using progesterone DBC-ELISA ${ }^{\circledR}$ kits.

\section{Statistical analysis}

All the statistical analysis was carried out in SPSS software version 20. The data records after experiment was compiled in Microsoft excel and further analyzed using descriptive statistics. Progesterone levels were analyzed using an ANOVA model with repeated measures to determine the significance difference between breeds, days and breed $\mathrm{x}$ day interactions. Significant difference was considered if $\mathrm{P}<0.05$.

\section{Results and Discussion}

The study was conducted on a total of 142 cows at Cattle Farm of Animal Genetics and Breeding Department, LUVAS. Irrespective of specific age of females the animals at spontaneous estrus were subjected to artificial insemination by adopting the AM/PM rule. Blood sampling from all the 142 animals was carried out on day 15 post-insemination and 
later from the animals which were confirmed pregnant ultrasonographically using $7 \mathrm{MHz}$ frequency transducer on day 28 (53 animals) and 45 (51 animals). Animals which were diagnosed with embryonic mortality on day 45 were also subjected to blood sampling.

The plasma progesterone concentrations from 51 (25 Sahiwal and 26 Hardhenu) pregnant animals on day 45 post insemination were analyzed and the results are presented in Table 1 and Figure 1. The results of Two-way ANOVA with repeated measures showed that there was significant $(\mathrm{p}<0.05)$ difference between breeds and days. However, breed $\mathrm{x}$ day interaction was not significant $(\mathrm{p}>0.05)$ for plasma progesterone concentrations. The plasma progesterone concentrations were significantly $(\mathrm{p}<0.05)$ higher in Hardhenu cows than Sahiwal cows at all day points (Day 15, 28 and 45). The plasma progesterone concentrations in Sahiwal cows increases significantly $(\mathrm{p}<0.05)$ from $1.18 \pm 0.40$ (Day
15) to $2.72 \pm 0.13$ (Day 45). The plasma progesterone concentrations in Hardhenu cows also increased significantly $(\mathrm{p}<0.05)$ from $1.78 \pm 0.05$ (Day 15) to 3.23 \pm 0.04 (Day 45).

The means bearing different superscripts ( $\mathrm{x}, \mathrm{y}$, z) differ significantly between days. The means bearing different superscripts $(\mathrm{a}, \mathrm{b})$ differ significantly between groups.

Further, the plasma progesterone concentrations from 28 Hardhenu (26 pregnant and 2 cows with embryonic mortality) were compared and the results are presented in Table 2 and Figure 2. The plasma progesterone concentrations were significantly higher in pregnant cows on all days (Day 15, 28 and 45) as compared to cows with embryonic mortality. The plasma progesterone concentrations in pregnant cows increased significantly $(\mathrm{p}<0.05)$ from $1.78 \pm 0.05$ (Day 15 ) to $3.23 \pm 0.04$ (Day 45).

Table.1 Plasma progesterone concentrations (Mean \pm SE) among pregnant Sahiwal and Hardhenu cows on day 15,28 and 45 post-insemination

\begin{tabular}{|c|c|c|c|}
\hline & $\begin{array}{c}\mathbf{P}_{\mathbf{4}}(\mathbf{n g} / \mathbf{m l}) \text { on } \\
\text { Day 15 }\end{array}$ & $\begin{array}{c}\mathbf{P}_{\mathbf{4}}(\mathbf{n g} / \mathbf{m l}) \text { on } \\
\text { Day 28 }\end{array}$ & $\begin{array}{c}\mathbf{P}_{\mathbf{4}}(\mathbf{n g} / \mathbf{m l}) \text { on } \\
\text { Day 45 }\end{array}$ \\
\hline $\begin{array}{c}\text { Sahiwal } \\
(\mathbf{n = 2 5})\end{array}$ & $1.18 \pm 0.40^{\mathrm{bz}}$ & $1.79 \pm 0.05^{\mathrm{by}}$ & $2.72 \pm 0.13^{\mathrm{bx}}$ \\
\hline Hardhenu (n=26) & $1.78 \pm 0.05^{\mathrm{az}}$ & $2.40 \pm 0.06^{\mathrm{ay}}$ & $3.23 \pm 0.04^{\mathrm{ax}}$ \\
\hline $\begin{array}{c}\text { Overall } \\
(\mathbf{n = 5 1 )}\end{array}$ & $1.48 \pm 0.05$ & $2.10 \pm 0.08$ & $2.98 \pm 0.08$ \\
\hline
\end{tabular}

Table.2 Plasma progesterone concentrations (Mean \pm SE) in pregnant and with embryonic mortality Hardhenu cows on day 15, 28 and 45 post-insemination

\begin{tabular}{|c|c|c|c|}
\hline & $P_{4}(\mathrm{ng} / \mathrm{ml})$ on Day 15 & $P_{4}(\mathrm{ng} / \mathrm{ml})$ on Day 28 & $P_{4}(\mathrm{ng} / \mathrm{ml})$ on Day 45 \\
\hline Pregnant $(n=26)$ & $1.78 \pm 0.05^{\mathrm{az}}$ & $2.40 \pm 0.07^{\mathrm{ay}}$ & $3.23 \pm 0.04^{\mathrm{ax}}$ \\
\hline $\operatorname{EM}(n=2)$ & $0.75 \pm 0.05^{b}$ & $1.35 \pm 0.15^{b}$ & $0.70 \pm 0.10^{b}$ \\
\hline Total $(n=28)$ & $1.70 \pm 0.07$ & $2.33 \pm 0.08$ & $3.05 \pm 0.13$ \\
\hline
\end{tabular}


Fig.1 Plasma progesterone concentrations (Mean \pm SE) among pregnant Sahiwal and Hardhenu cows on day 15, 28 and 45 post-insemination

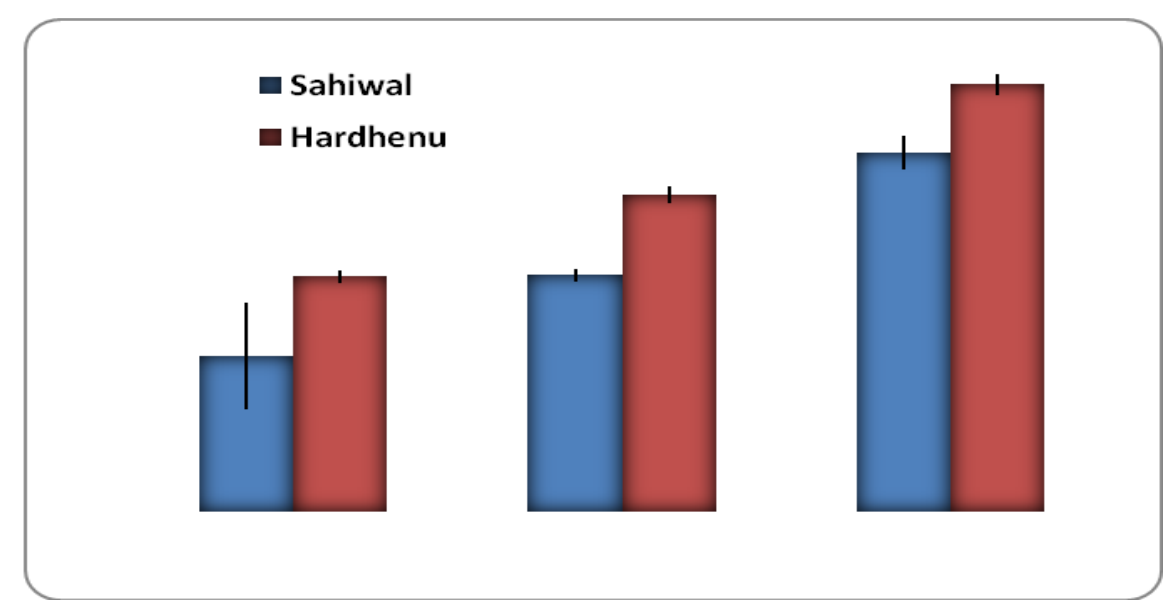

Fig.2 Plasma progesterone concentrations (Mean \pm SE) in Hardhenu pregnant and cows with embryonic mortality on day 15,28 and 45 post-insemination

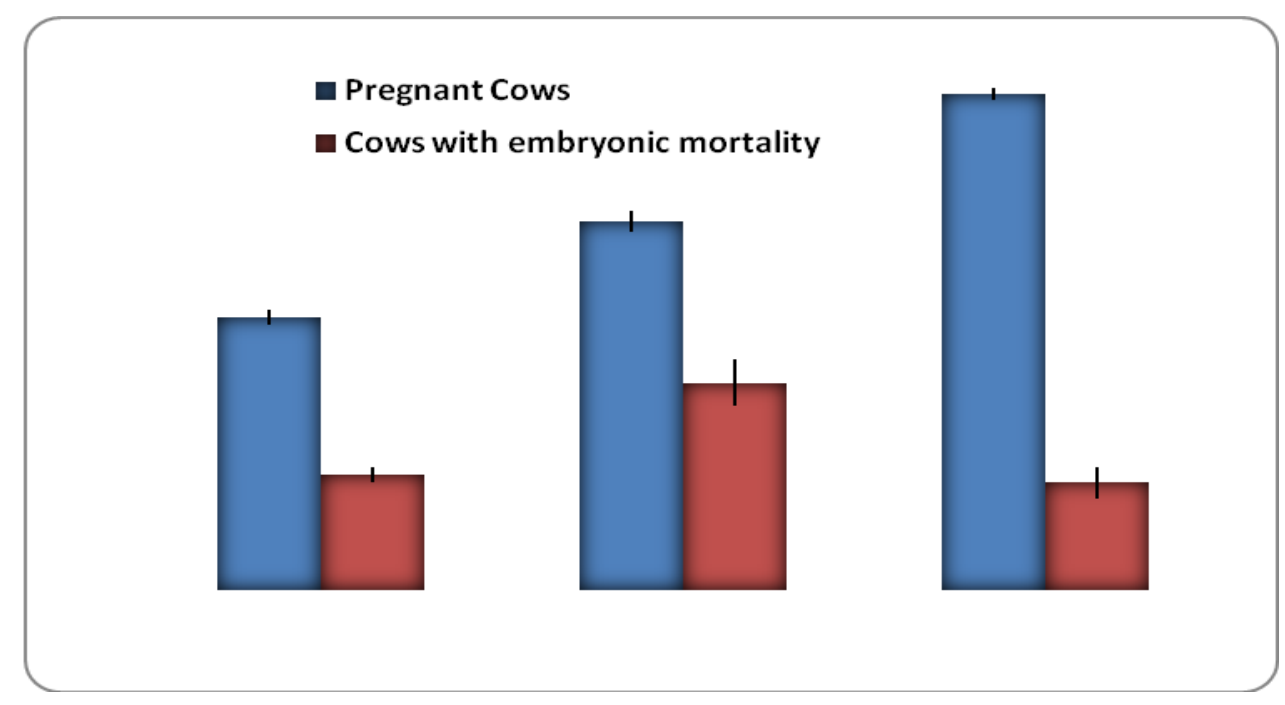

The plasma progesterone concentrations in cows with embryonic mortality increased remarkably from $0.75 \pm 0.05$ (Day 15) to $1.35 \pm 0.15$ (Day 28). However, after Day 28 it decreased drastically to $0.70 \pm 0.10$ on Day 45 . Since the animals suffered from EM were two in number, therefore statistical significance could not be carried out.

In the current investigation, the animals which were recorded with embryonic mortality had lower $\mathrm{P}_{4}$ concentration on day 15,28 and 45 $(0.75 \pm 0.05,1.35 \pm 0.15$ and $0.70 \pm 0.10 \mathrm{ng} / \mathrm{ml})$ as compared pregnant animals $(1.78 \pm 0.05$, $2.40 \pm 0.07$ and $3.23 \pm 0.04 \mathrm{ng} / \mathrm{ml}$ ) which approximated well with the findings of Mouiche et al., (2016).

Similar to our findings, Humblot et al., (1988) also reported that peripheral progesterone concentrations are lower at days 24 to 26 after $\mathrm{AI}$ in cows with late embryonic mortality than 
in pregnant animals. Similar to our findings, Hadiya et al., (2015) on day 21 of postinsemination observed the slight higher plasma $\mathrm{P}_{4}$ concentration within a range of 3.93 to $7.68 \mathrm{ng} / \mathrm{ml}$ with an average of $6.48 \pm 0.38 \mathrm{ng} / \mathrm{ml}$ in pregnant Gir and crossbred cattle. However, Prvanovic et al., (2009) estimated plasma progesterone concentrations on day $12,21,35$ postinsemination and concluded that it is impossible to determine embryonic mortality merely on the basis of progesterone profile, but it is easy to distinguish pregnant from non-pregnant cows, supposing cows to be more than 21 days pregnant. The plasma $\mathrm{P}_{4}$ concentrations after day 20 post-insemination in pregnant animals recorded in present study are in accordance with Raghorte et al., (2009) and Bhoraniya et al., (2011). It is very easy and accurate to distinguish non-pregnant cows from cows that have suffered early embryonic mortality.

The conclusion of the present study is, it was observed that the animals suffered with embryonic mortality had lower progesterone concentrations on day 15,28 and 45 postinsemination than the animals with normal pregnancy. Therefore, luteal insufficiency or other external factors could have been the cause of embryonic mortality.

\section{Acknowledgement}

The authors are highly thankful to the Dean, College of Veterinary Sciences for providing all the necessary facilities for conducting this study.

\section{References}

Bajaj, N.K. and Sharma, N. (2011). Endocrine causes of early embryonic death. An Overview: Current Research in dairy Sci., 3(1): 1-24.

Bajaj. N.K. (2001). Effects of herbal medication on endometritis in buffaloes. M.Sc. Thesis, Gujarat Agriculture University, Anand Campus, S.K. Nagar (Gujarat), India.

Bhoraniya, H.L., Dhami, A.J., Naikoo, M. and Divekar, B.S. (2011). Early pregnancy diagnosis through transrectal ultrasonography and plasma progesterone assay in Kankrej cows. Indian J. Anim. Reprod., 32(2): 23-26.

Campanile, G.N. (2007). Embryonic mortality in cows. Italian J. Anim. Sci., 6(2): 119-129.

Chaudhary, A.K. and Purohit, G.N. (2012). Ultrasonographic detection of early pregnancy loss in dairy cows. $J$. Animal Sci. Adv., 8: 706-710.

Committee On Reproductive Nomenclature (1972). Recommendations for standardizing bovine reproductive terms. Cornell. Vet., 62: 216-237.

Diskin, M.G. and Morris, D.G. (2008). Embryonic and early fetal losses in cattle and other ruminants. Reprod. Domest. Anim., 43(2): 260-267.

Hadiya, K.K., Dhami, A.J., Nakrani, B.B., Patel, J.A. and Sarvaiya, N.P. (2015). Predictive efficiency of USG and plasma progesterone assay for detection of early pregnancy and embryonic mortality in cattle. G.J.B.B., 4(1): 277-281.

Humblot, P., Camous, S., Martal, J., Charley, J., Jeanguyot, N., Thibier, M. and Sasser, R.G. (1988). Pregnancyspecific protein $\mathrm{B}$, progesterone concentrations and embryonic mortality in dairy cows. J. Reprod. Fert., 83: 215-223.

Kastelic, J.P., Bergfelt, D.R. and Ginther, O.J. (1991). Ultrasonic detection of the conceptus and characterization of intrauterine fluid on days 10 to 22 in heifers. Theriogenology. 35: 569-581.

Maurer, R.R. and Chenault, J.R. (1983). 
Fertilization failure and embryonic mortality in parous and non-parous beef cattle. J. Anim. Sci., 56: 11861189.

Mouiche, M.M.M., Sow, A., Kalandi, M., Nyabinwa, P., Ouedraogo, A.G. and Sawadogo, G.J. (2016). Detection of embryonic mortality using progesterone and bovine pregnancy associated glycoprotein assays following artificial insemination of Gobra Zebu cattle in Senegal. Int'l. J. Clin. Biochem., 3 (1): 143-150.

Prvanovic, N., Tomaskovic, A., Grizelj, J., Kocila, P. and Samardzija, M. (2009). Monitoring of early pregnancy and early embryonic mortality by ultrasound and determination of pregnancy-associated glycoproteins and progesterone in cows. Vet. Arhiv., 79: 259-267.

Raghorte, Y.M., Chinchkar, S.R., Sahatpure, S.K., Gawande, A.P., Gaikwad, S.M., Dhakate, M.S., Raut, J.D., Gote, S.G. and Verma, T. (2009). a) Progesterone concentration during Ovsynch protocol and b) Prediction of early pregnancy with serum progesterone level in buffalo heifers and postpartum buffaloes. Proceedings of $25^{\text {th }}$ Annual convention of ISSAR and National symposium held at Namakkal, Tamilnadu, Dec. 10-12, p: 43.

Roche, J.F., Bolandl, M.P. and McGeady, T.A. (1981). Reproductive wastage following A.I of heifers. Vet. Rec., 109: 401-404.

Sreenan, J. and Diskin, M. (1986). The extent and timing of embryonic mortality in the cow. In: embryonic mortality in farm animals, Sreenan, J. and Diskin, M. (Eds.). Martinus Nijhoff Publishers, Amsterdam, pp: 1-11.

Vanroose, G., De Kruif, A. and Van Soom, A. (2000). Embryonic mortality and embryo-pathogen interactions. Anim. Reprod. Sci., 60-61: 131-143.

Zavy, M.T. (1994). Embryonic Mortality in Cattle. In: Embryonic Mortality in Domestic Species, Zavy, M.T. and Geisert, R.D. (Eds.). CRC Press, Boca Raton, pp: 99-140.

\section{How to cite this article:}

Pinki Rani, R.K. Chandolia, Ravi Dutt, Nitin Soni, Anand Kumar Pandey, Gyan Singh, Sandeep Kumar and Dhaka, S.S. 2018. Circulating Progesterone Concentrations in Cows During Early Pregnancy and Embryonic Mortality Condition. Int.J.Curr.Microbiol.App.Sci. 7(07): 1448-1454. doi: https://doi.org/10.20546/ijcmas.2018.707.172 